\title{
EVALUATION OF USABILITY OF MALAYSIA DIABETES PREVENTION PROGRAM (MyDiPP) MOBILE APP - A PILOT STUDY
}

\author{
NURUL FATIHAH MOHD FAUZI ${ }^{1}$, SHARIFAH WAJIHAH WAFA ${ }^{1 *}$, MOHD IBRAHIM ABDULLAH ${ }^{1}$, \\ NARESH BHASKAR RAJ ${ }^{2}$, BARAKATUN NISAK MOHD YUSOF ${ }^{3}$, \\ NORKHAIRANI ABDUL RAWI ${ }^{4}$ and NURULHUDA MAT HASSAN ${ }^{5}$ \\ ${ }^{1}$ School of Nutrition and Dietetics, Faculty of Health Sciences, Gong Badak Campus, \\ Universiti Sultan Zainal Abidin, 21300 Kuala Terengganu, Malaysia \\ ${ }^{2}$ School of Rehabilitation Science, Faculty of Health Sciences, Gong Badak Campus, \\ Universiti Sultan Zainal Abidin, 21300 Kuala Terengganu, Malaysia \\ ${ }^{3}$ School of Nutrition and Dietetics, Faculty of Medicine and Health Sciences, \\ Universiti Putra Malaysia, 43400 Serdang, Selangor, Malaysia \\ ${ }^{4}$ Faculty of Informatics and Computing, Besut Campus, Universiti Sultan Zainal Abidin, \\ 22200 Besut, Terengganu, Malaysia \\ ${ }^{5}$ Faculty of Medicine, Universiti Sultan Zainal Abidin, Jalan Sultan Mahmud, \\ 20400 Kuala Terengganu, Malaysia \\ *E-mail: sharifahwajihah@unisza.edu.my
}

Accepted 20 October 2021, Published online 30 November 2021

\begin{abstract}
Malaysia is confronting a type 2 diabetes (T2DM) epidemic; around 3.9 million Malaysians have T2DM. Lifestyle modification intervention is effective in reducing or delaying the onset of T2DM among high-risk individuals. The Malaysia Diabetes Prevention Programme (MyDiPP) app is a lifestyle intervention digital therapy with multiple approaches (weight loss, dietary modification, physical activity, and quality of life). This study aimed to assess the usability of the MyDiPP mobile app among high-risk individuals in Kuala Terengganu. A random sample of 10 users was selected in the usability evaluation of the MyDiPP mobile app. Data collection methods included an online survey on the usability aspect of mobile apps in terms of usefulness, ease of use, satisfaction, and ease of learning. The results showed that MyDiPP mobile app is useful, easy to use, satisfying, and easy to learn from the high-risk adults' perspectives with slightly agree, moderately agree, and strongly agree to have the highest percentage. From these results, it can be inferred that, from the perspective of high-risk individuals, MyDiPP mobile app meets the usability aspects and can be used to help prevent the development of diabetes among at-risk adults.
\end{abstract}

Key words: Diabetes prevention program, mHealth, mobile app, usability test

\section{INTRODUCTION}

Diabetes is a condition with potential for long-term complications (American Diabetes Association, 2015), including ischemic heart disease, cerebrovascular disease, peripheral vascular disease, blindness, kidney disease, and neuronal damage. Besides the classical complications, type 2 diabetes mellitus (T2DM) has also been associated with reduced responsiveness of $\mathrm{T}$ cells, neutrophil activity, and impairment of the immune system

\footnotetext{
* To whom correspondence should be addressed.
}

(Muller et al., 2005; Peleg et al., 2007). In other words, people with diabetes have compromised immunity which primarily increased the risk of susceptibility and severity to infection (Talbot et al., 2012; Frydrych et al., 2018). For instance, amid COVID-19, studies have shown that people with diabetes or obese more prone to be admitted to the hospital and ICU if they are infected with COVID19. In addition, their death rate is also higher compared to the infected normal people (Bode et al., 2020; Petrilli et al., 2020; Wu \& McGoogan, 2020; Shi et al., 2020; Wang et al., 2020). Wang et al. (2020) reported that $72.2 \%$ of COVID-19 patients with 
comorbidities had to be admitted to the ICU compared to $37.3 \%$ of patients without comorbidities. Out of $72.2 \%, 22.2 \%$ of them had diabetes. Infection may be the precursor to complications of diabetes, such as hypoglycemia and ketoacidosis (Casqueiro et al., 2012).

In both developing and developed countries, the prevalence of diabetes has increased considerably over the past few decades and has become a primary health concern worldwide (Danaei et al., 2011). It has been estimated that around 463 million adults suffered from diabetes in 2019, and the number is growing rapidly in low- and middle-income countries. By 2045, the prevalence of diabetes is projected to increase to 700 million (Cho et al., 2018; International Diabetes Federation, 2019). In Malaysia, the overall prevalence of diabetes mellitus, whether diagnosed or undiagnosed, has increased more than doubled over the last two decades, rising from $8.3 \%$ in 1996 to $18.3 \%$ in 2019 , affecting approximately 3.9 million adults aged 18 years and above (Institute for Public Health, 2020).

The prevalence of prediabetes among adults worldwide has been estimated to be more than 260 million (6.4\%) (International Diabetes Federation, 2011) and in 2019, 373.9 million adults were diagnosed with impaired glucose tolerance (IGT) across the globe (International Diabetes Federation, 2019). This number is expected to rise to 453.8 million and 548.4 million in 2030 and 2045, respectively (International Diabetes Federation, 2019). Being overweight is one of the factors associated with a greater probability of both diabetes and prediabetes (Yach et al., 2006). In Malaysia, the prevalence of overweight and obesity among adults aged 18 years and above increased from $30 \%$ in 2015 to $30.4 \%$ in 2019 , and from $17.7 \%$ in 2015 to $19.7 \%$ in 2019 , respectively (Institute for Public Health, 2015; Institute for Public Health, 2020). People who have been diagnosed with prediabetes are at a significantly higher risk of developing diabetes (Tabák et al., 2012). Whereas approximately $37 \%$ of them will develop diabetes within four years if they continue to practice unhealthy or sedentary lifestyle habits (Knowler et al., 2002).

With the current pandemic situation, efforts should be made to ascertain potential strategies for early intervention with those at high risk of developing T2DM, such as through lifestyle modification. Lifestyle interventions are intended to assist individuals in preventing or delaying the onset of T2DM as well as the complications associated with it, by focusing on the two most modifiable risk factors for developing diabetes which is obesity and physical inactivity (Tabák et al., 2012).

Digital therapy is broadly classified as telemedicine and internet-based eHealth interventions (Mohr et al., 2014) as well as app-based mobile Health (mHealth) interventions delivered via smartphones or other mobile devices (Kramer et al., 2019). mHealth is the evolution of eHealth due to the rapid expansion of the internet which has overlapped the development of wireless communication as well as due to the widespread availability and use of smartphones (Duplaga \& Tubek, 2018). There are more than 97, 000 apps regarding healthcare and medicine (Aitken \& Ganntlett, 2013; Molina-Recio et al., 2015). Experts believed that mHealth could make significant improvements to healthcare delivery processes and also be of great benefit to the people where it can reduce cost, save time, has greater accessibility as well as easier and faster communication about diseases and health (Zuhal, 2018). The use of mHealth also has the potential to improve a person's lifestyle, nutrition, health, and other physiological states, behaviors, and overall quality of life (Hoque, 2016). A core part of the development of the app is the assessment of usability (Zaid et al., 2012). However, according to Fatima et al. (2019), about $95 \%$ of the available mHealth mobile apps have not been evaluated in terms of usability. A well-designed and highly usable app positively affect user engagement (Eysenbach, 2005). On the other hand, poor usability is related to low effectiveness and engagement (Eysenbach, 2005; Whitlock \& McLaughlin, 2012). Usability testing refers to how well an app works and whether it fulfills its intended purpose or not. Usability testing which is specified on the target population may be particularly useful for researchers or clinicians whose work focuses on these populations (Kaikkonen et al., 2005).

As diabetes can be prevented through healthy lifestyle modification, therefore it is important to encourage and promote such initiative through mHealth applications where it can reach a wider prospect. Malaysia Diabetes Prevention Program (MyDiPP) mobile app is an app developed specifically for Malaysian people at risk of developing diabetes to prevent them from getting diabetes through behavioral modification. It consists of educational lessons, health coaches, peer groups, and technology-enabled tools to track nutritional intake, physical activities, body weight, as well as HbA1c level. The educational lessons have been adopted from publicly available materials from the United States Diabetes Prevention Program (US DPP) of the Centre for Disease Control and Prevention (CDC), combined with Malaysian Dietary Guidelines (MDG) and the current Management of T2DM Clinical Practice Guidelines (CPG) from the Ministry of Health Malaysia by referring to the Diabetes Malaysia; the module was featured in a mobile app. The materials have been modified to meet the needs and cultural sensitivity of Malaysians. Therefore, this study was conducted to evaluate the usability of the 
MyDiPP mobile app after it has been used by adults at high risk of developing diabetes.

\section{MATERIALS AND METHODS}

\section{Participants}

This pilot study has been performed on individuals at high risk of developing diabetes. The risk of developing diabetes was assessed using the American Diabetes Association (ADA) Diabetes Risk Test that was distributed through Google Form. Existing literature suggests that $10 \%$ of the sample projected for the larger parent study should be a sample size for the pilot study (Connelly, 2008). Therefore, in this study, 10 adults were enrolled. Participants in this study included a convenience sample from Kuala Terengganu, Malaysia. They are deemed eligible if they are 18-65 years old, with a body mass index (BMI) of $\geq 23 \mathrm{~kg} / \mathrm{m}^{2}$ (WHO Expert Consultation, 2004), high risk for diabetes (diabetes risk test score $\geq 5$ (Lindstrom \& Tuomilehto, 2003) or $\mathrm{HbAlc}$ of $38-44 \mathrm{mmol} / \mathrm{mol}$ or $5.6-6.2 \%$ (Clinical Practice Guidelines, 2018)), own a smartphone (only Android) and fluent in Malay or English language. The exclusion criteria are those with a clinical history of diabetes or newly diagnosed with diabetes at the time of screening where their HbAlc level is $\geq 45$ $\mathrm{mmol} / \mathrm{mol}$ or $\geq 6.3 \%$ (Clinical Practice Guidelines, 2018), participants with cognitive impairment or other causes which can interfere with their participation (for being physically disabled or have any mental health conditions that include eating or alcohol/ substance abuse).

\section{Point of analysis}

This research aimed to evaluate the usability of the MyDiPP mobile app for individuals at risk of diabetes. The study only covered the general aspects of the mobile app and did not focus on any specific parts of the mobile app. There are four categories of usability that were evaluated in this study, which are:

- Usefulness: The ability of the user to accomplish specific goals in the environment.

- Ease of use and ease of learning: Resources used (time, money, and mental effort) when a system-supported task is performed.

- Satisfaction: The user's level of comfort and overall system acceptance.

According to Norkhairani et al. (2017), these categories are as suggested by Zaharias (2004), Ardito et al. (2004), and Ardito et al. (2006) which were by the standard of ISO (ISO, 1993).

\section{Questionnaire setup}

The questionnaire consists of two sections. The first section focuses on demographic components such as age, gender, body weight, glycated hemoglobin (HbA1c) level, level of education, ICT knowledge level, and experience on any kind of computer machine. The second section of the questionnaire was adapted by Norkhairani et al. (2017) and contains 30 questions that evaluate four categories of usability, which are usefulness (8 questions), ease of use (11 questions), ease of learning (4 questions), and satisfaction (7 questions). Table 1 presents the items in each category of usability. The participants' response was measured using a 7 points Likert Scale where the scale labeled with Strongly Disagree (StD), Moderately Disagree (MD), Slightly Disagree (SID), Neither Agree nor Disagree (NDA), Slightly Agree (SIA), Moderately Agree (MA) and Strongly Agree (StA).

\section{Procedure}

The participants were briefed on how to use MyDiPP mobile app and the self-enrolment process was demonstrated. They were given a month to use the mobile app. During a month, they were asked to $\log$ in their diet and physical activity in an app every day, weigh themselves and log their weight in the app every week, communicate with the health coach through private messages or group discussion in the app, and read the module and answer the related questions once a week. At the end of the month, participants were provided with a Google Form link to answer a questionnaire regarding the usability aspect of the MyDiPP mobile app. The link was accessible to the participants for about a week. Each participant can only complete the survey once.

\section{Data collection and analysis}

Participants' responses were collected through Google Form. Participants were given a link to access and answer the online survey. They were contacted by telephone call to remind them to answer the survey and the link was given through WhatsApp. The results obtained were analyzed according to the four main sections which are usefulness, ease of use, ease of learning, and satisfaction. Data entry and statistical analysis were performed using IBM SPSS Statistics Version 22. From there frequency percentage, mean and standard deviation were calculated using descriptive statistics. The data of frequency percentage for usability evaluation was reported in a spider web chart to provide a better understanding of the data for each item evaluated throughout the four different sections of usability analysis. 
Table 1. Items in each category of usability

\begin{tabular}{ll}
\hline Category & Item \\
\hline Usefulness & It helps me be more effective (Q1) \\
& It helps me be more productive (Q2) \\
It is useful (Q3) & It gives me more control over the activities in my life (Q4) \\
& It makes the things I want to accomplish easier to get done (Q5) \\
& It saves me time when I use it (Q6) \\
It meets my needs (Q7) & It does everything I would expect it to do (Q8) \\
\hline Ease of use & It is easy to use (Q1) \\
It is simple to use (Q2) & It is user friendly (Q3) \\
It requires the fewest steps possible to accomplish what I want to do with it (Q4) & It is flexible (Q5) \\
Using it is effortless (Q6) \\
I can use it without written instructions (Q7) \\
I don't notice any inconsistencies as I use it (Q8) \\
Both occasional and regular users would like it (Q9) \\
I can recover from mistakes quickly and easily (Q10) \\
I can use it successfully every time (Q11)
\end{tabular}

\section{RESULTS}

A total of 10 respondents participated in this study, consisting of $80 \%$ female and $20 \%$ male. The mean $\pm \mathrm{SD}$ of age, body mass index (BMI), and $\mathrm{HbAlc}$ level of all respondents were $30.60 \pm 4.17$ years old, $28.20 \pm 3.68 \mathrm{~kg} / \mathrm{m}^{2}$, and $5.09 \pm 0.22 \%$, respectively. All of them also attained a tertiary level of education as their highest level of education, with $70 \%$ of them having a moderate level of ICT knowledge and most of them had experience using a computer for 9 to 10 years $(60 \%)$.

Usefulness refers to how useful the MyDiPP mobile app is to the participants in helping them practice healthy lifestyle behavior to prevent T2DM. For this section, based on the chart, a high percentage was obtained for SIA, MA, and StA which are indicated by the blue, green, and purple lines. It proves that the MyDiPP mobile app is acceptable in terms of usability from the high-risk adults' perspectives. Therefore, high-risk adults can actively use MyDiPP mobile apps to help them fight the risk of diabetes through healthy lifestyle modification. Figure 1 summarizes the findings for this section.
Figure 2 shows the results for questions about the aspect of ease of use. A high percentage was seen on SIA, MA, and StA even though some of the participants answered NDA, MD, and SID for certain questions. However, the yellow, orange, and grey lines in the chart indicated that $10 \%$ of the respondents chose NDA (Q3, Q8, and Q9), MD (Q6 and Q11), and SID (Q7, Q10, and Q11) where these questions related to user-friendly, effortless, can be used without written instruction, inconsistencies, the occasional and regular user would like it, can recover from mistakes quickly and easily, as well as can use it successfully every time.

For ease of learning the results were summarized in Figure 3. The results obtained show a high percentage of agreement among participants where all the questions scored SIA, MA, and StA. The questions in this section related to how fast and easy the participants learned about the app.

For satisfaction, Figure 4 shows that the majority of respondents agree with all the questions asked in this section except for Q5 where only one respondent neither agrees nor disagrees (NDA) that the app is wonderful. This is indicated by the yellow marked line in the chart. This means that 


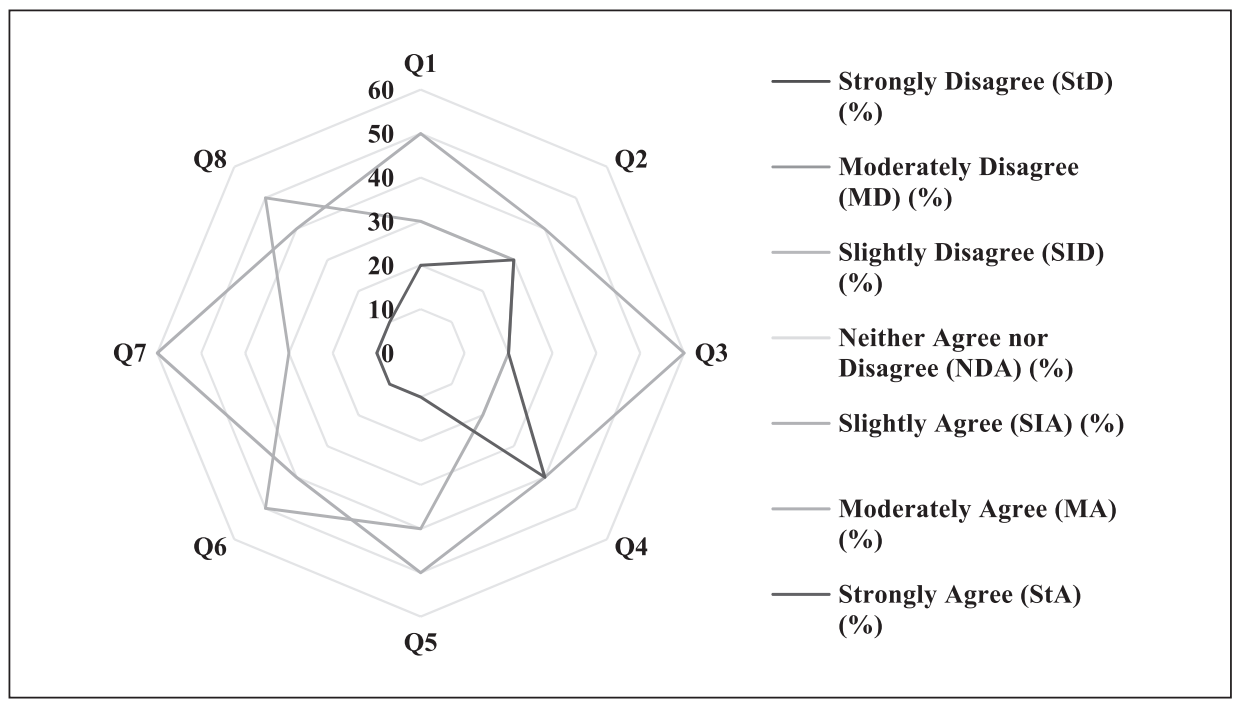

Fig. 1. Result of usefulness.

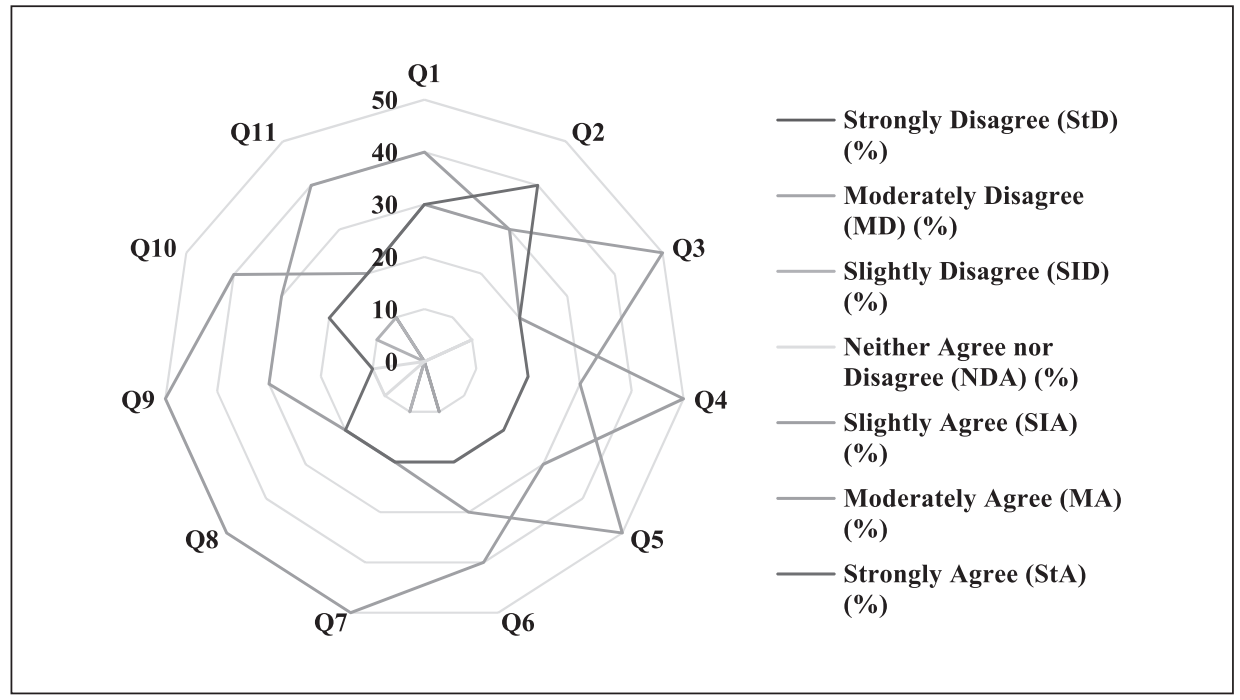

Fig. 2. Result of ease of use.

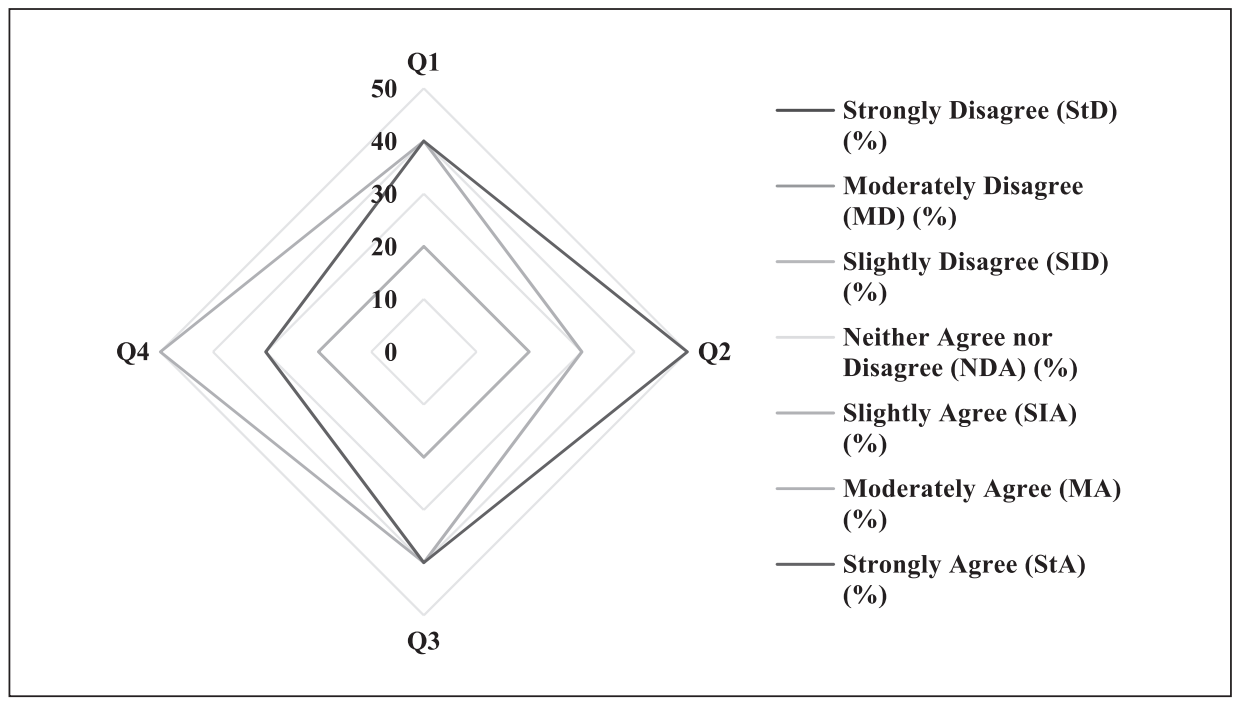

Fig. 3. Result of ease of learning. 


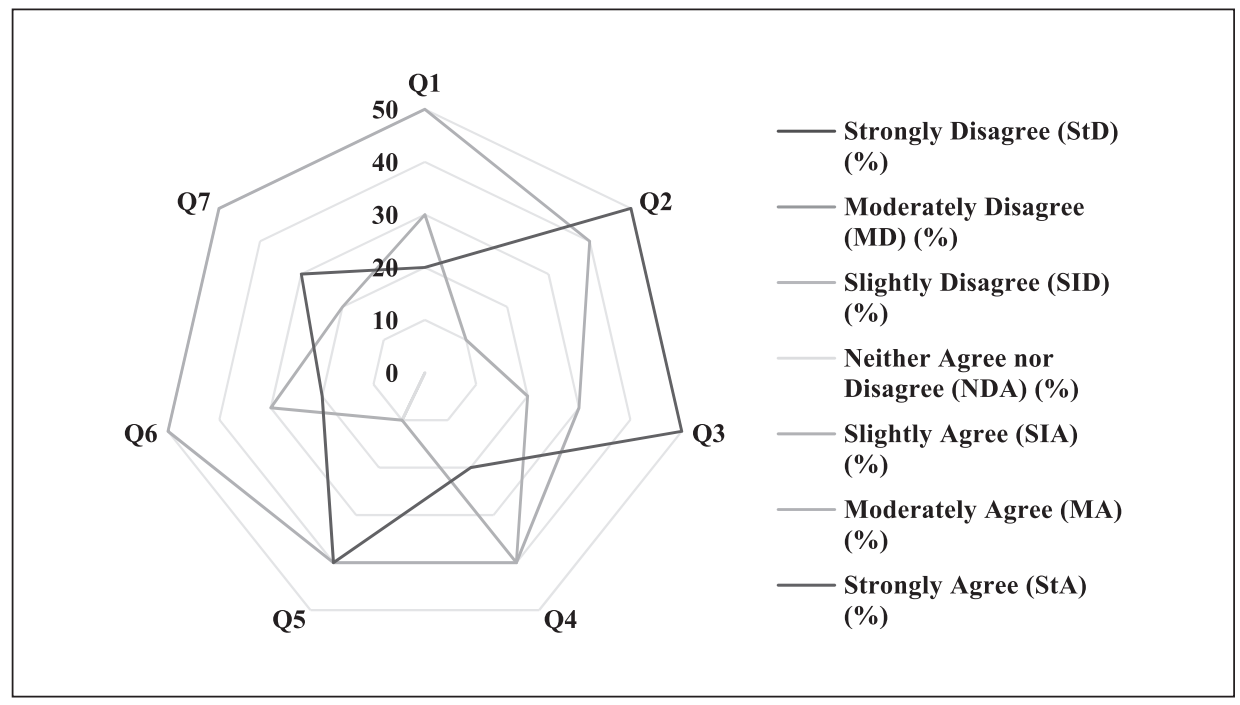

Fig. 4. Result of satisfaction.

the respondent is not fully satisfied with how the app looks, therefore further investigation is needed to identify weaknesses from this perspective.

\section{DISCUSSION}

MyDiPP mobile app is a kind of mHealth (mobile health) application that aims to help individuals at risk of developing diabetes practice healthy behavior and at the end of the day help them prevent T2DM. mHealth is a term invented for the improvement of health outcomes using mobile and wireless devices (Kamana, 2016). mHealth may not be the replacement for skilled healthcare, but empowering people with information related to primary, secondary, and tertiary prevention, may play a supporting role in diabetes prevention as well as management so that they can make knowledgeable decisions about their lifestyle and behavior (International Diabetes Federation, 2014). Before testing clinical effectiveness, evaluation of usability was viewed as a prerequisite to guarantee that the application will function properly, be acceptable, and meet the needs of the target population (Brown et al., 2013; O’Malley et al., 2014). Relevant to the objective of the present study, results showed that each usability dimension measured for the MyDiPP mobile app was highly and positively rated by the majority of participants at high risk of developing diabetes. Findings from this study showed that our participants perceived MyDiPP mobile app as useful in helping them prevent diabetes. Liu et al. (2011) reported that mHealth apps that included data visualization, integration with Internet of Things devices, and/or the ability to track were rated more favorably by users.
According to Alloghani et al. (2015), perceived usefulness is the extent to which users believe the health-related services provided by mobile health apps will benefit them. All of the participants agreed that the MyDiPP mobile app is useful to them. Therefore, they agree that the diabetes prevention program offered by MyDiPP mobile app will be beneficial to them. In short, an individual's likelihood of adopting mobile health apps increases as he or she gains access to the benefits of these apps (Yee et al., 2019). When people view apps as beneficial to their health care outcomes, favorable attitudes toward the app development, which result in a favorable behavioral intention to use the app (Deng et al., 2012).

As defined by Weichbroth (2020), ease of use is the perceived level of effort required by the user to use the application. Any technology is considered useful if people can employ it easily or if the system works without any effort (Ghalandari, 2012). Therefore, regardless of the usefulness given by the mobile health apps, people's interest in using them will decrease when the app is too complex to use, or when the efforts dedicated to its use outweigh the value of using it (Yee et al., 2019). This might explain why $10 \%$ of respondents disagree that the use of the MyDiPP mobile app is effortless, can be used without written instruction, can recover from mistakes easily and quickly, and can use it successfully every time. In addition, connectivity also might negatively affect the usability of the mobile app where network conditions such as data transfer speed, reliability, and signal strength may vary according to time and place. Besides that, different mobile devices' display resolutions may yield different usability test results like the ability to visualize data in graphics is 
influenced by the display resolution (Martin et al., 2011). On the other hand, when people perceive that a new system is comfortable, easy to use, and easier to use than another, the desire or likelihood of adopting the system increases (Yee et al., 2019).

Ease of learning depicts the capability of the software product to enable the user to learn its application. In this study, the majority of participants (40\%) moderately agree and strongly agree that they can learn to use MyDiPP mobile app quickly and easily. Meanwhile, $50 \%$ of them strongly agree and moderately agree that they can easily remember how to use the app as well as quickly become skillful in using the app respectively. According to Stoll et al. (2017), there is a moderate to the high correlation between scores for system ease of learning and system ease of use. Even though a small percentage of respondents disagree with some items in the ease of use section, the majority of the respondents are still in agreement that the app provides ease of use to them. For instance, items such as easy to use, simple to use, requires the fewest steps possible to accomplish something, and flexibility was positively rated by all of the respondents and these might explain why a high percentage of agreement among the respondents in terms of ease of learning of MyDiPP mobile app.

According to research, the perceived usability of a product is significantly influenced by the product's attractiveness (Chawda et al., 2005). It asserted that what is aesthetically pleasing is also usable (Tractinsky et al., 2000). Attractiveness is associated with design, animation, or visual elements that capture the user's attention in one go (Hsiao et $a l ., 2016)$. It has the greatest influence on usability ratings in the field of mobile computing, followed by effectiveness and efficiency (Quinn \& Tran, 2010). The first stage of attraction entails capturing the user's attention (Sutcliffe, 2002). Visual elements in technological products have the potential to elicit users' emotions and affective responses (Silvennoinen et al., 2014). Using appropriate media, such as dynamic media (video \& speech) that are attention-directing over static media (images and text), is important (Sutcliffe, 1999). Since this usability study only evaluates the app objectively, therefore the exact reason why one participant rated MyDiPP mobile app as neither attractive nor unattractive is not known. So, we can say that the use of only static media in the app might be the reason why that participant rated the app as NDA. In contrast, Lingaard \& Dudek (2003) demonstrated that attractiveness does not always translate into high usability ratings. These contradictory findings might be due to the priority set by the users whether their objective was to have fun or to complete tasks. According to Hassenzahl (2008), perceived usability is more important when people aim to complete tasks, whereas hedonic, pleasure-oriented characteristics are more important when their objective is to have fun. Moreover, visual design in the user interface can adversely affect usability where applications that make extensive use of color or visual elements are likely to have a lower usability "score" than wellthought-out designs that are simpler in appearance and do not increase the user's cognitive load (Healthcare Information and Management Systems Society, 2012).

\section{CONCLUSION}

The performed study has attained the goal to gather feedback from individuals at high risk of developing diabetes about the usability aspects of the MyDiPP mobile app. The four aspects of usability examined show a high percentage of Agree for each category. However, eight points need to be given the attention which are the questions related to user-friendly, effortless, can be used without written instruction, inconsistencies, the occasional and regular user would like it, can recover from mistakes quickly and easily, can use it successfully every time as well as the app attractiveness. However, the response to these matters is low with only $10 \%$ of the respondents disagreeing. Overall, it can be inferred that the MyDiPP mobile app for the prevention of diabetes fulfills the usability aspects from the highrisk adults' perspective. These findings proved that MyDiPP mobile app can help in the prevention of diabetes among this population, even though some improvements especially regarding ease of use and attractiveness are needed to make it much better.

\section{ACKNOWLEDGEMENTS}

The module for this study was adopted from publicly available materials from the United States Diabetes Prevention Program (US DPP) of Centres for Disease Control and Prevention (CDC), combined with Malaysian Dietary Guidelines (MDG) and the current Management of T2DM Clinical Practice Guidelines (CPG) from the Ministry of Health Malaysia and was translated into the Malay language as well as underwent forward-backward translation by Khuzaiton Zakaria, Aveleena Afzan Hassan, and Nor Fazura Md Zulkifle who were language lecturers at Universiti Malaysia Kelantan, Malaysia. 


\section{REFERENCES}

Aitken, M. \& Gauntlett, C. 2013. Patient apps for improved healthcare: From novelty to mainstream. IMS Institute for Healthcare Informatics, Parsippany.

Alloghani, M., Hussain, A., Al-Jumeily, D. \& Abuelma'atti, O. 2015. Technology acceptance model for the use of M-health services among health related users in UAE, in: International Conference on Developments of E-Systems Engineering. Dubai, United Arab Emirates, pp. 213-217.

American Diabetes Association 2015. Diagnosis and classification of diabetes mellitus. Diabetes Care, 38(Suppl 1): S8-S16.

Ardito, C., De Marsico, M., Lanzilotti, R., Levialdi, S., Roselli, T., Rossano, V. \& Tersigni, M. 2004. Usability of e-learning tools, in: Proceedings of the Working Conference on Advanced Visual Interfaces. Gallipoli (LE), Italy, pp. 270-283.

Ardito, C., Costabile, M.F., De Marsico, M., Lanzilotti, R., Levialdi, S., Roselli, T. \& Rossano, V. 2006. An approach to usability evaluation of e-learning applications. Universal Access in the Information Society, 4(3): 270-283.

Bode, B., Garrett, V., Messler, J., McFarland, R., Crowe, J., Booth, R. \& Klonoff, D.C. 2020. Glycemic characteristics and clinical outcomes of COVID-19 patients hospitalized in the United States. Journal of Diabetes Science and Technology, 14(4): 813-821.

Brown III, W., Yen, P.-Y., Rojas, M. \& Schnall, R. 2013. Assessment of the health IT usability evaluation model (Health-ITUEM) for evauating mobile health (mHealth) technology. Journal of Biomedical Informatics, 46(6): 1080-1087.

Casqueiro, J., Casqueiro, J. \& Alves, C. 2012. Infections in patients with diabetes mellitus: A review of pathogenesis. Indian Journal of Endocrinology and Metabolism, 16(Suppl 1): S27-S36.

Chawda, B., Craft, B., Cairns, P., Heesch, D. \& Rüger, S. 2005. Do "attractive things work better"?: An exploration of search tool visualisations, in: Proceedings of 19th British HCI Group Annual Conference: The Bigger Picture. Edinburgh, UK, pp. 46-51.

Cho, N.H., Shaw, J.E., Karuranga, S., Huang, Y., da Rocha Fernandes, J.D., Ohlrogge, A.W. \& Malanda, B. 2018. IDF Diabetes Atlas: Global estimates of diabetes prevalence for 2017 and projections for 2045. Diabetes Research and Clinical Practice, 138: P271-81.

Clinical Practice Guidelines (CPG) for the Management of T2DM. 2018. 5th Ed.
Connelly, L.M. 2008. Pilot studies. Medsurg Nursing: Official Journal of The Academy of MedicalSurgical Nurses, 17(6): 411-2.

Danaei, G., Finucane, M.M., Lu, Y., Singh, G.M., Cowan, M.J., Paciorek, C.J., Lin, J.K., Farzadfar, F., Khang, Y.H., Stevens, G.A., Rao, M., Ali, M.K., Riley, L.M., Robinson, C.A., Ezzati, M. \& Global Burden of Metabolic Risk Factors of Chronic Diseases Collaborating Group (Blood Glucose). 2011. National, regional, and global trends in fasting plasma glucose and diabetes prevalence since 1980: Systematic analysis of health examination surveys and epidemiological studies with 370 country-years and 2.7 million participants. Lancet, 378(9785): 31-40.

Deng, A., Zhang, L. \& Zhang, J. 2012. Applying technology acceptance model to explore the determinants of mobile health service: from the perspective of public user, in: Eleventh Wuhan International Conference on E-business. pp. 406411.

Duplaga, M. \& Tubek, A. 2018. mHealth-areas of application and the effectiveness of interventions. Public Health Management/Zdrowie Publiczne i Zarzqdzanie, 16(3): 155-166.

Eysenbach, G. 2005. The law of attrition. Journal of Medical Internet Research, 7(1): e11.

Fatima, Z., Azham, H. \& Haslina, M. 2019. Factors affecting mobile health application for chronic diseases. Journal of Telecommunication, Electronic and Computer Engineering, 10(111): $77-81$.

Frydrych, L.M., Bian, G., O’Lone, D.E., Ward, P.A. \& Delano, M.J. 2018. Obesity and type 2 diabetes mellitus drive immune dysfunction, infection development, and sepsis mortality. Journal of Leukocyte Biology, 104(3): 525-534.

Ghalandari, K. 2012. The effect of performance expectancy, effort expectancy, social influence and facilitating conditions on acceptance of E-Banking services in Iran: The moderating role of age and gender. Middle-East Journal of Scientific Research, 12(6): 801-807.

Hassenzahl, M. 2008. Aesthetics in interactive products: Correlates and consequences of beauty. In: Product Experience. H.N.J. Schifferstein and P.P.M. Hekkert (Eds.). Elsevier, Amsterdam, pp. 287-302.

Healthcare Information and Management Systems Society. 2012. Selecting a mobile app: Evaluating the usability of medical applications [WWW Document]. URL http://s3.amazonaws.com/ rdcmshimss/files/production/public/ HIMSS guidetoappusabilityv 1 mHIMSS.pdf (accessed 6.13.21). 
Hoque, M.R. 2016. An empirical study of mHealth adoption in a developing country: the moderating effect of gender concern. BMC Medical Informatics and Decision Making, 16(51).

Hsiao, C.H., Chang, J.J. \& Tang, K.Y. 2016. Exploring the influential factors in continuance usage of mobile social apps: Satisfaction, habit, and customer value perspectives. Telematics and Informatics, 33(2): 342-355.

Institute for Public Health (IPH), National Institutes of Health, Ministry of Health Malaysia. 2020. National Health and Morbidity Survey (NHMS) 2019: Vol. I: NCDs - Non-Communicable Diseases: Risk Factors and Other Health Problems.

International Diabetes Federation. 2011. IDF Diabetes Atlas. 5th Ed. International Diabetes Federation, Brussels.

International Diabetes Federation. 2014. How mobile health can help tackle the diabetes epidemic and strengthen health systems: International Diabetes Federation (IDF) response to the public consultation on the European Commission's Green Paper on mobile health. Diabetes Research and Clinical Practice, 105(2): 271-2.

International Diabetes Federation. 2019. IDF Diabetes Atlas. 9th Ed. International Diabetes Federation, Brussels.

ISO. 1993. ISO DIS 9241-11: Guidelines for specifying and measuring usability.

Kaikkonen, A., Kekäläinen, A., Cankar, M., Kallio, T. \& Kankainen, A. 2005. Usability testing of mobile applications: a comparison between laboratory and field testing. The Journal of Usability Studies, 1(1): 4-16.

Kamana, M. 2016. Investigating Usability Issues of mHealth Apps for Elderly People: A Case Study Approach (Master Thesis). Blekinge Institute of Technology Karlskrona Sweden.

Knowler, W.C., Barrett-Connor, E., Fowler, S.E., Hamman, R.F., Lachin, J.M., Walker, E.A., Nathan, D.M. \& Diabetes prevention program research group. 2002. Reduction in the incidence of type 2 diabetes with lifestyle intervention or metformin. The New England Journal of Medicine, 346(6): 393-403.

Kramer, U., Borges, U., Fischer, F., Hoffmann, W., Pobiruchin, M. \& Vollmar, H.C. 2019. DNVFMemorandum-Health and medical apps. Gesundheitswesen, 81(10): e154-e70.

Lindgaard, G. \& Dudek, C. 2003. What is this evasive beast we call user satisfaction?. Interacting with Computers, 15(3): 429-452.

Lindstrom, J. \& Tuomilehto, J. 2003. The diabetes risk score: A practical tool to predict type 2 diabetes risk. Diabetes Care, 26(3): 725-731.
Liu, C., Zhu, Q., Holroyd, K.K. \& Seng, E.K. 2011. Status and trends of mobile-health applications for iOS devices: A developer's perspective. Journal of Systems and Software, 84(11): 20222033.

Martin, C., Flood, D., Sutton, D.R., Aldea, A., Harrison, R. \& Waite, M. 2011. A systematic evaluation of mobile applications for diabetes management, in: Human-Computer Interaction INTERACT 2011 - $13^{\text {th }}$ IFIP TC 13 International Conference. Lisbon, Portugal, pp. 466-469.

Mohr, D.C., Schueller, S.M., Montague, E., Burns, M.N. \& Rashidi, P. 2014. The behavioral intervention technology model: an integrated conceptual and technological framework for eHealth and mHealth interventions. Journal of Medical Internet Research, 16(6): e146.

Molina-Recio, G., García-Hernández, L., CastillaMelero, A., Palomo-Romero, J.M., Molina-Luque, R., Sánchez-Muñoz, A.A., Arauzo-Azofra, A. \& Salas-Morera, L. 2015. Impact of Health Apps in Health and Computer Science Publications: A Systematic Review from 2010 to 2014. In: Bioinformatics and Biomedical Engineering. F. Ortuño and I. Rojas (Eds.). Springer, Cham, pp. 24-34.

Muller, L.M.A.J., Gorter, K.J., Hak, E., Goudzwaard, W.L., Schellevis, F.G., Hoepelman, A.I.M. \& Rutten, G.E.H.M. 2005. Increased risk of common infections in patients with type 1 and type 2 diabetes mellitus. Clinical Infectious Diseases, 41: 281-8.

Norkhairani, A.R., Normala, R., Abd Rasid, M., Maizan, M.A. \& Mohamad Afendee, M. 2017. The usability of elarning management system from student perspective. World Applied Sciences Journal, 35: 147-152.

O’Malley, G., Dowdall, G., Burls, A., Perry, I.J. \& Curran, N. 2014. Exploring the usability of a mobile app for adolescent obesity management. JMIR mHealth and uHealth, 2(2): e29.

Peleg, A.Y., Weerarathna, T., McCarthy, J.S. \& Davis, T.M. 2007. Common infections in diabetes: Pathogenesis, management and relationship to glycaemic control. Diabetes Metabolism Research and Review, 23: 3-13.

Petrilli, C.M., Jones, S.A., Yang, J., Rajagopalan, H., O’Donnell, L., Chernyak, Y., Tobin, K.A., Cerfolio, R.J., Francois, F. \& Horwitz, L.I. 2020. Factors associated with hospitalization and critical illness among 4,103 patients with COVID19 disease in New York City. BMJ, 369: m1966. 
Quinn, J.M. \& Tran, T.Q. 2010. Attractive phones don't have to work better: Independent effects of attractiveness, effectiveness, and efficiency on perceived usability, in: Proceedings of the SIGCHI Conference on Human Factors in Computing Systems. Atlanta, GA, USA, pp. 353362.

Shi, Q., Zhang, X., Jiang, F., Zhang, X., Hu, N., Bimu, C., Geng, J., Yan, S., Guan, Y., Xu, D., He, G., Chen, C., Xiong, X., Liu, L., Li, H., Tao, J., Peng, Z. \& Wang, W. 2020. Clinical characteristics and risk factors for mortality of COVID-19 patients with diabetes in Wuhan, China: A two-center, retrospective study. Diabetes Care, 43: 13821391.

Silvennoinen, J., Vogel, M. \& Kujala, S. 2014. Experiencing visual usability and aesthetics in two mobile application contexts. Journal of Usability Studies, 10(1): 46-62.

Stoll, R.D., Pina, A.A., Gary, K. Amresh, A. 2017. Usability of a smartphone application to support the prevention and early intervention of anxiety in youth. Cognitive and Behavioural Practice, 24(4).

Sutcliffe, A.G. 1999. User-centred design for multimedia applications, in: Proceedings IEEE International Conference on Multimedia Computing and Systems. Florence, Italy, pp. 116-123.

Sutcliffe, A.G. 2002. Assessing the reliability of heuristic evaluation for website attractiveness and usability, in: Proceedings of the $35^{\text {th }}$ Hawaii International Conference on System Sciences.

Tabák, G., Herder, C., Rathmann, W., Brunner, E.J. \& Kivimäk, M. 2012. Prediabetes: A high-risk state for developing diabetes. Lancet, 379(9833): 2279-90.

Talbot, H.K., Coleman, L.A., Crimin, K., Zhu, Y., Rock, M.T., Meece, J., Shay, D.K., Belongia, E.A. \& Griffin, M.R. 2012. Association between obesity and vulnerability and serologic response to influenza vaccination in older adults. Vaccine, 30(26): 3937-3943.

Tractinsky, N., Katz, A.S. \& Ikar, D. 2000. What is beautiful is usable. Interacting with Computers, 13(2): 127-145.
Wang, D., Hu, B., Hu, C., Zhu, F., Liu, X., Zhang, J., Wang, B., Xiang, H., Cheng, Z., Xiong, Y., Zhao, Y., Li, Y., Wang, X. \& Peng, Z. 2020. Clinical characteristics of 138 hospitalized patients with 2019 novel coronavirus-infected pneumonia in Wuhan, China. JAMA, 323(11): 1061-1069.

Weichbroth, P. 2020. Usability of mobile applications: A systematic literature study. IEEE Access, PP(99): 1-1.

Whitlock, L.A. \& McLaughlin, A.C. 2012. Identifying usability problems of blood glucose tracking apps for older adult users. Proceedings of the Human Factors and Ergonomics Society Annual Meeting, 56(1): 115-119.

WHO Expert Consultation. 2004. Appropriate bodymass index for Asian populations and its implications for policy and intervention strategies. Lancet, 363(9403): 157-63.

Wu, Z. \& McGoogan, J.M. 2020. Characteristics of and important lessons from the coronavirus disease 2019 (COVID-19) outbreak in China: Summary of a report of 72314 cases from the Chinese Center for Disease Control and Prevention. JAMA, 323(13): 1239-1242.

Yach, D., Stuckler, D. \& Brownell, K.D. 2006. Epidemiologic and economic consequences of the global epidemics of obesity and diabetes. Natural Medicine, 12(1): 62-66.

Yee, T.S., Lim, C.S. \& Wong, S.C. 2019. Patient's intention to use mobile health app. Journal of Management Research, 11(3): 18.

Zaharias, P. 2004. Usability and e-learning: the road towards integration. eLearn Magazine, June, pp. 4.

Zaid, B., Jamaludin, R. \& Wafaa, B. 2012. A comparative study of usability methods for mobile applications. International Journal of Scientific and Engineering Research, 3(8): 1-4.

Zuhal, H. 2018. The advantages and disadvantages of the mHealth applications and the intention to use among smartphone users. International Journal of Mechanical Engineering and Technology, 9(12): 943-947. 